\title{
Erratum to: Exploiting smart spaces for interactive TV applications development
}

\author{
M. Mohsin Saleemi • Natalia Díaz Rodríguez • \\ Johan Lilius
}

Published online: 11 September 2014

(C) Springer Science+Business Media New York 2014

\section{Erratum to: J Supercomput DOI 10.1007/s11227-014-1183-0}

The authors would like to correct authorship credits of the original publication.

Natalia Díaz Rodríguez contributed to the research presented in this article but was mistakenly excluded from the authorship list. The correct list is given in this erratum.

The online version of the original article can be found under doi:10.1007/s11227-014-1183-0.

M. M. Saleemi $(\bowtie) \cdot$ N. Díaz Rodríguez · J. Lilius

Åbo Akademi University, Turku, Finland

e-mail: mohsin.saleemi@gmail.com

N. Díaz Rodríguez

e-mail:ndiaz@abo.fi

J. Lilius

e-mail: johan.lilius@abo.fi 